\title{
Editorial: Marine Biodiversity Observation Network (MBON)
}

\author{
Dominique Pelletier ${ }^{1 *}$, Juan Carlos Azofeifa-Solano ${ }^{2}$, Enrique Montes $^{3}$ and \\ Frank Edgar Muller-Karger ${ }^{4}$ \\ ${ }^{1}$ Unité Ecologie et Modèles pour l'Halieutique, Département Ressources Biologiques et Environnement, Institut Français de \\ Recherche pour l'Exploitation de la Mer, Nantes, France, ${ }^{2}$ Centro de Investigación en Ciencias del Mar y Limnología \\ (CIMAR), Universidad de Costa Rica, San José, Costa Rica, ${ }^{3}$ Ocean Chemistry and Ecosystems Division, National Oceanic \\ and Atmospheric Administration Atlantic Oceanographic and Meteorological Laboratory, Miami, FL, United States, ${ }^{4}$ College \\ of Marine Science, University of South Florida, St Petersburg, FL, United States
}

Keywords: MBON, ocean observing, marine essential biodiversity variables (EBV), ecosystem-based management, species distribution, marine monitoring

\section{Editorial on the Research Topic}

\section{Marine Biodiversity Observation Network (MBON)}

A growing human population depends on healthy ocean ecosystems for economic and social benefits including high quality food, pharmaceuticals and other materials, coastal protection, recreation, transportation, and renewable energy. Governments and scientists around the world have recognized the need for information on changes in marine biodiversity that are relevant to these ecosystem services. This includes practical information to implement conservation and

\section{OPEN ACCESS}

Edited and reviewed by: Hervé Claustre,

Centre National de la Recherche Scientifique (CNRS), France

*Correspondence: Dominique Pelletier dominique.pelletier@ifremer.fr

Specialty section: This article was submitted to Ocean Observation, a section of the journal Frontiers in Marine Science

Received: 09 December 2021 Accepted: 29 December 2021 Published: 24 January 2022

Citation:

Pelletier D, Azofeifa-Solano JC, Montes E and Muller-Karger FE (2022) Editorial: Marine Biodiversity Observation Network (MBON).

Front. Mar. Sci. 8:832328 doi: 10.3389/fmars.2021.832328 sustainable development targets such as those agreed to under the Convention on Biological Diversity (CBD) and the U.N. Sustainable Development Goals (SDG). Biodiversity observations are fundamental to enable global assessments such as those by the Intergovernmental Platform on Biodiversity and Ecosystem Services (IPBES) and the UN World Ocean Assessment.

Important questions are where particular species populations and hotspots of multiple marine species occur at any time and how their distributions are changing. Standardized data sets and products are needed to answer questions on whether present place-based conservation measures are suitable for a particular location. Standardized approaches are also needed for adaptive management strategies given climate change scenarios and projected ocean uses. These factors have confounding effects on changes in life in the ocean that affect phenology, distribution of species including invasives and alien species, and decreases in the abundance of specific organisms or groups of organisms. Understanding how this affects the ecology and benefits that people and other forms of life may derive (or lose) from such changes requires monitoring and studying the abundance and distribution of species from the coast to the deep sea.

The Marine Biodiversity Observation Network (MBON) is a global community of practice for the sustained collection, curation, and analysis of marine biodiversity data for information on the status and trends of life in the sea. MBON operates within the framework of the Group on Earth Observations (GEO) Biodiversity Observation Network (GEO BON) to inform society of changes on ecosystem services. The role of the MBON is to broker relationships and activities. MBON members benefit from learning emerging and best practices, new collaborations, and co-authored publications.

The Frontiers MBON Research Topic invited a broader set of actors to contribute to this community of practice. A total of fifteen articles were published under the Research Topic. 
They showcase different facets of marine biodiversity research in polar, temperate and tropical ecosystems, in coastal and deep waters. Emerging technologies are providing new insights into marine life and enhancing our capacity to gather highquality observations faster and over larger spatial domains. The use of molecular methods including environmental DNA (eDNA) is exploding around the world, with applications to evaluate presence and function from viruses to top predators and to explore human impacts on the ocean. One example published under the Research Topic is a survey of biodiversity of ichthyoplankton around Japan (Kim et al.). Another study provided the first assessment of jellyfish biodiversity in the Florida Keys, USA (Ames et al.).

Several articles feature protocols for processing imagery to quantify biodiversity. Obst et al. use molecular methods and image-based identification methods in comparative studies of benthic diversity, as well as for detecting non-indigenous species, working with Autonomous Reef Monitoring Structures (ARMS). They proposed an ARMS-MBON to advance standard protocols for monitoring hard-bottom environments. Bravo et al. used artificial intelligence to evaluate macroalgae and sessile organisms on rocky shores across the American continent, from Patagonia (Argentina) to Canada, including the Galapagos Islands (Ecuador). Livore et al. expanded a study of rocky shore biodiversity to include satellite-derived assessments of biogeography or "Seascapes" of Kavanaugh et al. (2021).

Much progress is being made with imaging devices including autonomous video landers to quantify biodiversity and behavior of organisms in the water column and on the ocean bottom. Giddens et al. describes an autonomous benthic lander platform with a baited camera system to conduct stationary video surveys of deep-sea megafauna, sponsored by the National Geographic Society Exploration Technology Lab. Pelletier et al. describe a standardized workflow for remote underwater video to assess fishes and habitats in coastal areas, using unbaited video cameras.

Two articles combine remote sensing data with in situ physical and biological measurements. Montes et al. also uses the satellite-derived "Seascapes" to illustrate how phytoplankton communities coincide with biogeographic provinces that can be mapped quickly with satellites using a case study of the Florida Keys National Marine Sanctuary (FKNMS, USA). Barceló et al. use satellite images to evaluate oceanographic predictor variables of epipelagic fish communities in the Northeast Pacific Ocean.

Other studies use more traditional methods to evaluate the status of specific organisms and communities. Bowlby et al. address the issue of natural and post-release mortality for particularly vulnerable shark species through archival satellite tags. Sudo et al. evaluate seagrass area cover in 9 countries in Southeast Asia and find that more than half of the seagrass beds declined at rates of over $10 \%$ per year since the late 1990 s due to coastal development, fisheries and aquaculture, and natural factors such as typhoons and tsunamis. They make recommendations for large-scale, regional management strategies. Barboza et al. highlight the relevance of ghost crabs as indicator species to reflect response to anthropogenic stressors and changes in environmental conditions.

In summary, these papers emphasize the utility and applications of biodiversity information. They show scalability and the importance of standardized protocols to enable large-scale, regional assessments. Communities of practice like MBON and regional efforts such as the MBON Pole to Pole of the Americas ( $\mathrm{MBON} \mathrm{P} 2 \mathrm{P}$ ) showcase the value of collaborations and sharing protocols for data collection, processing, curation, and publication (Bravo et al.; Guerra-Castro et al.; Livore et al.; Mendez et al.). The studies show how collaborations can be established across large geographies and different countries to lower the cost of methods and generate syntheses that have a greater scope than possible otherwise (Giddens et al.; Kim et al.; Livore et al.; Pelletier et al.). Overall, the articles document many approaches to evaluate Essential Biodiversity Variables (EOV: phytoplankton, zooplankton, benthic invertebrates, fishes, macroalgae, sea grass, and coral cover), and show that this is a necessary step to construct Essential Biodiversity Variables including time series of maps of biodiversity.

It is encouraging to see the community come together under networking frameworks like MBON. This effort continues as $\mathrm{MBON}$ is a core partner in the Marine Life 2030 Programme endorsed by the UN Decade of Ocean Science for Sustainable Development, providing evidence-based science in support of marine conservation, sustainable development, and improving human health everywhere.

We thank the authors of these papers, the many people involved in such studies for their contributions and their willingness to share them broadly, and the staff at Frontiers for their advice and support through this process.

\section{AUTHOR CONTRIBUTIONS}

DP and FM-K wrote the draft. EM and JA-S revised the editorial. All authors contributed to the article and approved the submitted version.

\section{FUNDING}

This is a contribution to the Marine Biodiversity Observation Network (MBON) of the Group on Earth Observations Biodiversity Observation Network. The MBON work was funded under the US National Ocean Partnership Program (NASA, NOAA, U.S. IOOS, BOEM, and ONR) through NASA grants NNX14AP62A, 80NSSC20K0017, and 80NSSC18K0318; and NOAA IOOS Award NA19NOS0120199. Additional support was provided by NSF Grant No. 1728913 (the OceanObs RCN). 


\section{REFERENCES}

Kavanaugh, M. T., Bell, T., Catlett, D., Cimino, M. A., Doney, S. C., Klajbor, W., et al. (2021). Satellite remote sensing and the marine biodiversity observation network: current science and future steps. Oceanography 34, 62-79. doi: 10.5670/oceanog.2021.215

Conflict of Interest: The authors declare that the research was conducted in the absence of any commercial or financial relationships that could be construed as a potential conflict of interest.

Publisher's Note: All claims expressed in this article are solely those of the authors and do not necessarily represent those of their affiliated organizations, or those of the publisher, the editors and the reviewers. Any product that may be evaluated in this article, or claim that may be made by its manufacturer, is not guaranteed or endorsed by the publisher.

Copyright (c) 2022 Pelletier, Azofeifa-Solano, Montes and Muller-Karger. This is an open-access article distributed under the terms of the Creative Commons Attribution License (CC BY). The use, distribution or reproduction in other forums is permitted, provided the original author(s) and the copyright owner(s) are credited and that the original publication in this journal is cited, in accordance with accepted academic practice. No use, distribution or reproduction is permitted which does not comply with these terms. 